\title{
Growth of Hierarchically Structured High-Surface Area Alumina on FeCrAl Alloy Wires
}

\author{
Chandni Rallan, ${ }^{1}$ Aaron Akah, ${ }^{2}$ Patrick Hill, ${ }^{1}$ and Arthur Garforth ${ }^{1}$ \\ ${ }^{1}$ The University of Manchester, SCEAS, Manchester M13 9PL, UK \\ ${ }^{2}$ Saudi Aramco, Research and Development Centre, Dhahran, Saudi Arabia \\ Correspondence should be addressed to Aaron Akah; akahchi@yahoo.com
}

Received 20 August 2013; Accepted 28 October 2013

Academic Editors: A. Bhattacharyya and A. Facchetti

Copyright (c) 2013 Chandni Rallan et al. This is an open access article distributed under the Creative Commons Attribution License, which permits unrestricted use, distribution, and reproduction in any medium, provided the original work is properly cited.

\begin{abstract}
The formation of metastable alumina phases due to the oxidation of commercial FeCrAl alloy wires ( $0.5 \mathrm{~mm}$ thickness $)$ at various temperatures and time periods has been examined. Samples were isothermally oxidised in air using a thermogravimetric analyzer (TGA). The morphology of the oxidised samples was analyzed using an Electronic Scanning Electron Microscope (ESEM) and $\mathrm{X}$-ray on the surface analysis was done using an Energy Dispersive X-Ray (EDX) analyzer. The technique of X-Ray Diffraction (XRD) was used to characterize the phase of the oxide growth. The entire study showed that it was possible to grow high-surface area gamma alumina on the $\mathrm{FeCrAl}$ alloy wire surfaces when isothermally oxidised above $800^{\circ} \mathrm{C}$ over several hours.
\end{abstract}

\section{Introduction}

Modern day car-exhaust systems use catalysts supported on ceramic monoliths. The last decade has seen a move towards metallic monoliths affording improved conversion and selectivity [1]. The use of catalysts supported on metal for packed bed catalytic reactions has been limited [2]. A structured catalyst with an alumina wash coat deposited on a highly conductive support, such as a FeCr alloy, has the potential to eliminate the heat transfer limitations in catalytic processes [1,3-5]. An adherent alumina wash coat on metal supports remains a challenge both to ensure that the support is anchored when thermal cycling is inherent in the operation of fixed bed reactors and to ensure that sufficient active catalyst is available to maintain required conversions.

The growth of transient metastable aluminas $\left(\theta_{-}, \gamma^{-}\right)$on foils when oxidised at temperatures of $800^{\circ} \mathrm{C}-1000^{\circ} \mathrm{C}$ for varied time periods has been reported [6-8]. During the phase transformation of the transient aluminas, there are particular oxidation parameters which result in the growth of a $\gamma-\mathrm{Al}_{2} \mathrm{O}_{3}$ layer which has properties of high-surface area and porosity. The structured morphology helps improve the adherence of a coating layer and also forms a base for synthesis of other supporting catalysts [9].
This paper aims to give a better understanding of the growth of the $\gamma-\mathrm{Al}_{2} \mathrm{O}_{3}$ layer by the controlled oxidation of $\mathrm{FeCrAl}$ alloy wires on a small scale (TGA) and laboratory scale (muffle furnace). Conditions are optimised for wires of $0.5 \mathrm{~mm}$ thickness with characterisation using ESEM and EDX. Further characterisation of the alumina phase by XRD was attempted.

\section{Experimental}

2.1. Material. FeCrAl alloy wires of thickness $0.5 \mathrm{~mm}$ with a chemical composition of $72.8 \% \mathrm{Fe}, 22 \% \mathrm{Cr}, 5 \% \mathrm{Al}, 0.1 \%$ $\mathrm{Y}$, and $0.1 \% \mathrm{Si}$ were used. The wires were commercially manufactured and supplied by GoodFellow. The wires were annealed in a continuous furnace at $1100^{\circ} \mathrm{C}$ prior to being supplied.

\subsection{Method}

2.2.1. Pretreatment. The wire was cut into strips of length $10-$ $12 \mathrm{~cm}$ which were then sandpapered (Emery cloth fine grade sandpaper) to remove any oxide layer [10] which might have been formed during the annealing process at the manufacturing site. Following this, a three-step chemical treatment 
described by Wu et al. [11] was carried out to remove any silicon deposits which might occur during sandpapering. The wires were first subjected to a caustic wash in $0.1 \mathrm{M} \mathrm{KOH}$ (Fisher Scientific) for 10 minutes followed by an acid wash in $0.1 \mathrm{M} \mathrm{HNO}_{3}$ (Sigma-Aldrich) for the same time. The final step was an ultrasonic bath in acetone (Fisher Scientific) for 30 minutes followed by an ultrasonic bath in deionised water.

2.2.2. Thermal Oxidation. Samples were isothermally oxidised and analyzed using the Q5000-IR (TA Instruments). The thermogravimetric analyzer (TGA) was used to study the weight change of the samples when isothermally oxidised and considering the scale of the experiment, the TGA was utilized as a small scale thermal oven. Six samples of FeCrAl alloy wires, each weighing $50 \mathrm{mg}( \pm 1 \%)$, were placed in ceramic pans. Each sample was oxidised in air (constant flow rate $50 \mathrm{~mL} / \mathrm{min}$ ) at a ramp rate of $10^{\circ} \mathrm{C} / \mathrm{min}$, isothermally oxidised at temperatures between $800^{\circ} \mathrm{C}$ and $1200^{\circ} \mathrm{C}$, and analyzed at various sampling times of $0.5 \mathrm{~h}-16 \mathrm{~h}$.

2.2.3. Surface Morphology. The varied surface morphology of the oxidised wire samples was analysed using an Electronic Scanning Electron Microscope (Quanta 200 FEI). Each wire sample was examined using the ESEM under high vacuum conditions and coated with gold by the method of physical vapour deposition to enable improved image quality.

2.2.4. Chemical Analysis. Using an Energy Dispersive XRay Spectrometer (EDAX Genesis), an elemental analysis was done on the surface of the oxidised samples to obtain the varied composition. Multiple spots were analyzed to ensure uniformity and also to obtain an average elemental composition.

2.2.5. Phase Analysis. Using the Philips X'Pert X-Ray Diffraction, experiments were performed on the samples in the $2 \theta$ range of $30^{\circ}-50^{\circ}$ and a scanning speed of $0.009^{\circ} / \mathrm{min}$. Slit widths of $1 / 4^{\circ}$ and $1 / 2^{\circ}$ were used for all the experiments. A qualitative chemical phase analysis was performed on the oxide layer grown on the alloy wire.

\section{Results}

Four sets of results have been presented from each technique of analysis. First a thermal analysis study was carried out followed by characterization of the oxide layer using the ESEM, EDX, and XRD.

3.1. TGA. Thermogravimetric analysis was used to study the weight change taking place during oxidation as a function of temperature and time. Each sample was oxidised isothermally for $16 \mathrm{~h}$ at temperatures between $800^{\circ} \mathrm{C}$ and $1200^{\circ} \mathrm{C}$. Figure 1 shows the weight change taking place at $1000^{\circ} \mathrm{C}$ with a weight gain of $0.54 \%(\sim 0.3 \mathrm{mg})$ within $12 \mathrm{~h}$. Table 1 details the weight change after $16 \mathrm{~h}$ at $800^{\circ} \mathrm{C}-1200^{\circ} \mathrm{C}$.

To optimize the operating temperature samples were initially oxidised isothermally for $16 \mathrm{~h}$ for varying temperatures of $800^{\circ} \mathrm{C}-1200^{\circ} \mathrm{C}$ and the weight change during oxidation
TABLE 1: Weight change for isothermal oxidation at $800^{\circ} \mathrm{C}-1200^{\circ} \mathrm{C}$ for $16 \mathrm{~h}$.

\begin{tabular}{lc}
\hline & Weight change (\%) \\
\hline $800^{\circ} \mathrm{C}$ & 0.03 \\
$900^{\circ} \mathrm{C}$ & 0.21 \\
$1000^{\circ} \mathrm{C}$ & 0.53 \\
$1200^{\circ} \mathrm{C}$ & 0.52 \\
\hline
\end{tabular}

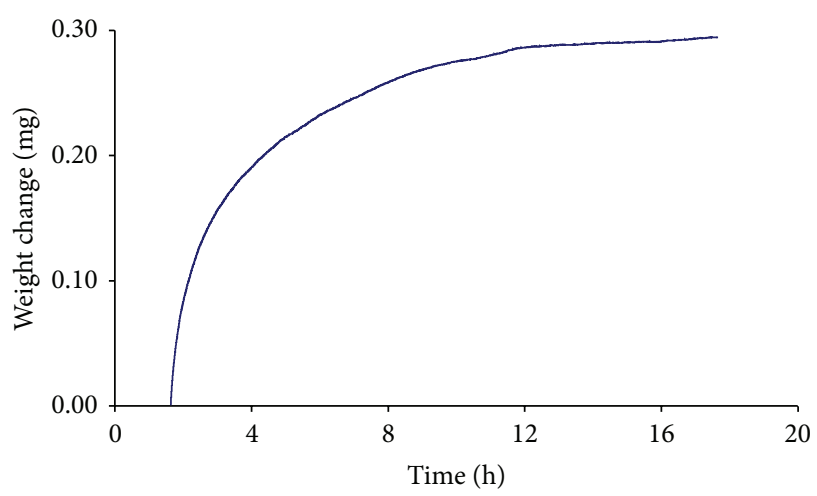

FIGURE 1: TGA data showing change in weight when isothermally oxidized for $16 \mathrm{~h}$ at $1000^{\circ} \mathrm{C}$.

was studied using the TGA. Maximum weight change could be seen when the samples were oxidised at $1000^{\circ} \mathrm{C}$ for $16 \mathrm{~h}$ (Table 1). At this temperature the weight change appeared to stabilize after a time period of $10 \mathrm{~h}$, the occurrence of which can be attributed to the loss of an - $\mathrm{OH}$ ion, causing a possible phase transformation taking place on the surface of the alloy wire, resulting in the formation of a more stable $\alpha-\mathrm{Al}_{2} \mathrm{O}_{3}$.

3.2. ESEM Characterization. The ESEM was used to analyze $\mathrm{FeCrAl}$ alloy samples at different stages of treatment studying the varied morphology and the changes occurring during oxidation.

Figure 2(a) shows the image of the wire prior to being subjected to any treatment and Figure 2(b) shows the surface once the samples have been pretreated and the difference in surface roughness is apparent. Previous work has shown that an increase in surface texture enhances the growth of the oxide layer [10].

3.2.1. Effect of Temperature on Surface Morphology. A comparison of the surface structure when oxidised isothermally for $16 \mathrm{~h}$ at different temperatures in the range of $800^{\circ} \mathrm{C}$ $1200^{\circ} \mathrm{C}$ is shown in Figure 3. The surface appears to be smooth when oxidised at $800^{\circ} \mathrm{C}$, but with increasing temperature a platelet formation can be seen which at higher temperatures $\left(1100^{\circ} \mathrm{C}\right)$ begins to sinter. At $900^{\circ} \mathrm{C}$ short alumina oxide platelets appear to be formed on the surface which at $1000^{\circ} \mathrm{C}$ appear to have been transformed into a dense growth of platelets.

3.2.2. Effect of Time on Surface Morphology. Following the temperature study, a time optimization study was carried 


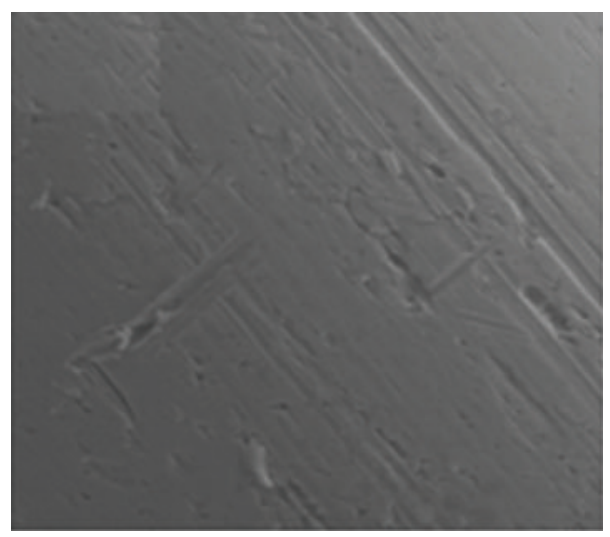

(a)

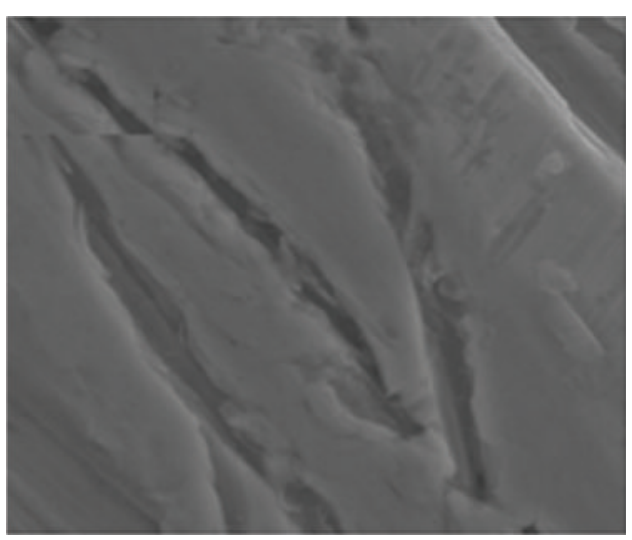

(b)

FIGURE 2: Wire morphology (a) as supplied and (b) after initial pretreatment.

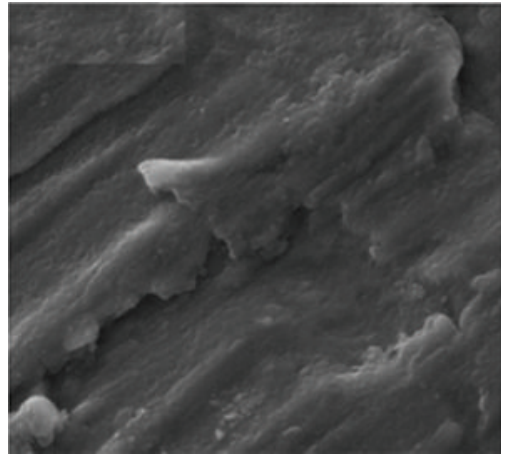

(a) $800^{\circ} \mathrm{C}$

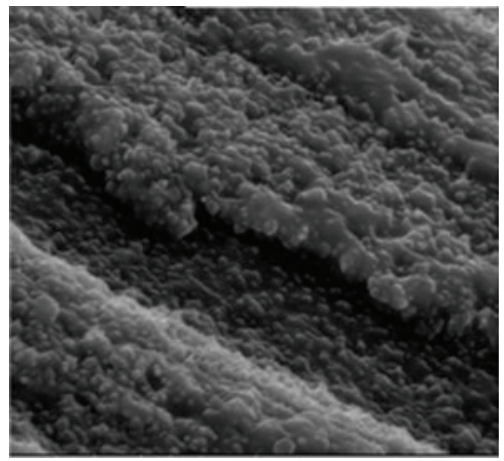

(b) $900^{\circ} \mathrm{C}$

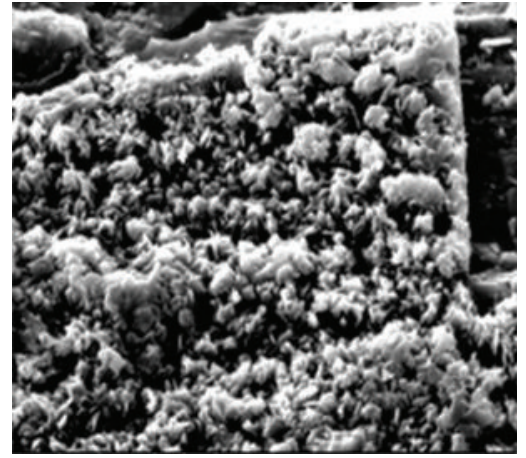

(c) $1000^{\circ} \mathrm{C}$

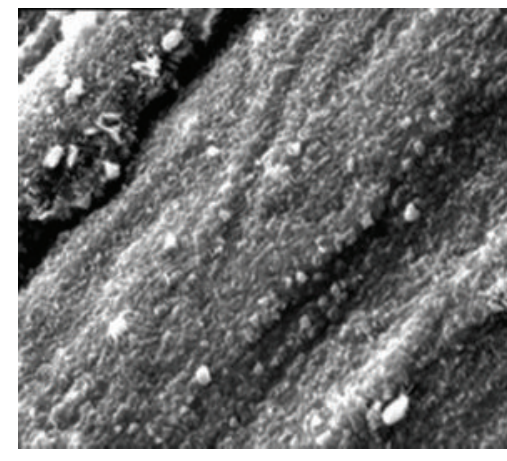

(d) $1100^{\circ} \mathrm{C}$

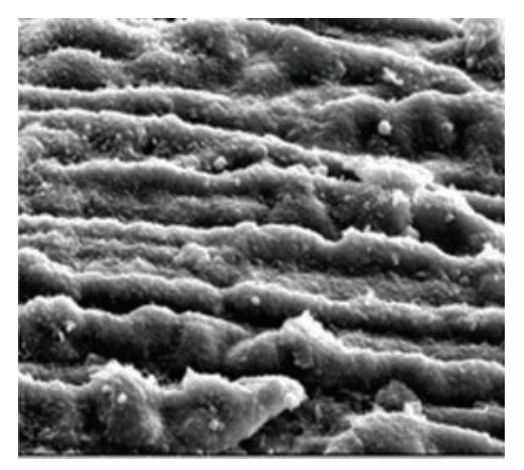

(e) $1200^{\circ} \mathrm{C}$

FIGURE 3: Varied morphology when isothermally oxidised at $800^{\circ} \mathrm{C}-1200^{\circ} \mathrm{C}$ for $16 \mathrm{~h}$.

out again using the TGA. Samples were isothermally oxidised at $1000^{\circ} \mathrm{C}$ for varying time periods between $0.5 \mathrm{~h}$ and $16 \mathrm{~h}$. Figure 4 shows the varied morphology at the different sampling times. Although a platelet-like morphology can be seen to be formed on the surface (as early as $0.5 \mathrm{~h}$ ), they are short and flat during the initial stages of thermal oxidation. With increasing time these platelets appear to transform into $\alpha-\mathrm{Al}_{2} \mathrm{O}_{3}$ nodules which form nucleation centres for further densification and growth of new platelets. Finally by $16 \mathrm{~h}$ these platelets sinter producing a more condensed phase.
The alloy surface shown in Figure 5 has long randomly oriented whiskers formed on the alloy surface after $8 \mathrm{~h}$ of isothermal oxidation at $1000^{\circ} \mathrm{C}$. Twining of platelets can be seen from the image.

A section of oxide growth on the alloy wire is shown in Figure 6. The dense growth of platelets can be seen and also an indication of a phase transformation of the oxide layer is obtained from the image. It is only at increased magnifications of $6000 \mathrm{x}-50000 \mathrm{x}$ that the varied surface morphology can be seen. At lower magnifications the surface appears to be smooth with no distinct features. 


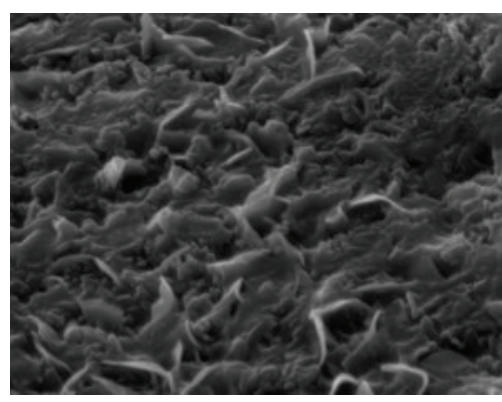

(a) $0.5 \mathrm{~h}$

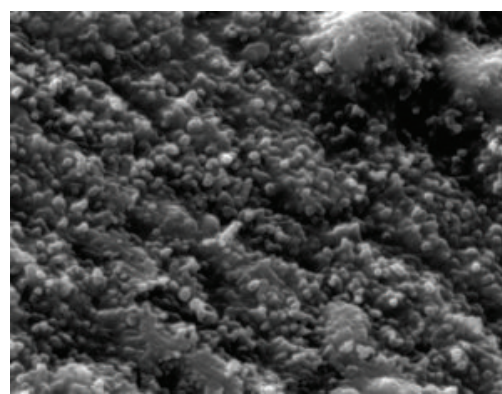

(d) $4 \mathrm{~h}$

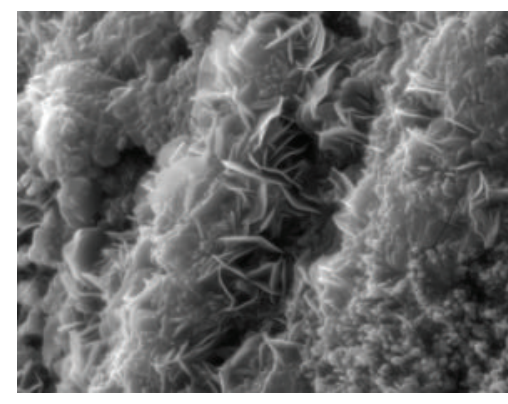

(b) $1 \mathrm{~h}$

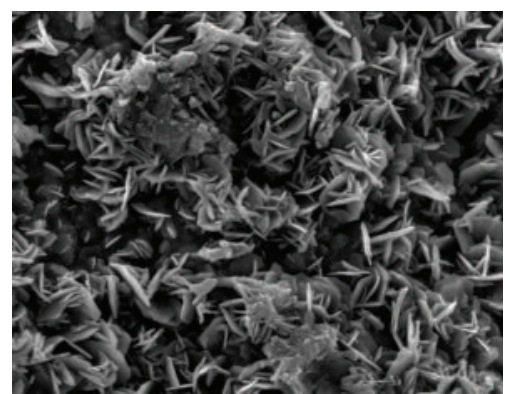

(e) $8 \mathrm{~h}$

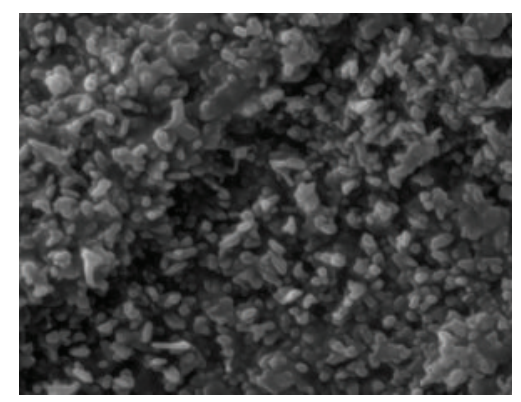

(c) $2 \mathrm{~h}$

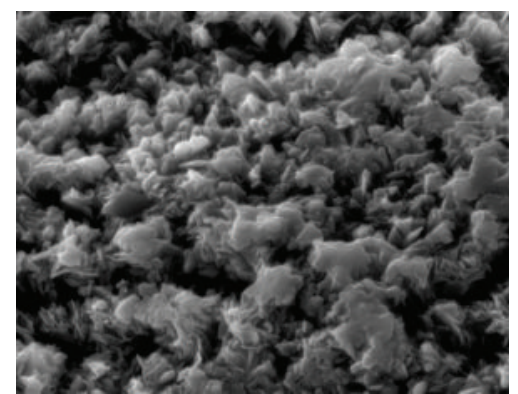

(f) $16 \mathrm{~h}$

FIGURE 4: Varied morphology when isothermally oxidized at $1000^{\circ} \mathrm{C}$ for $0.5 \mathrm{~h}-16 \mathrm{~h}$.
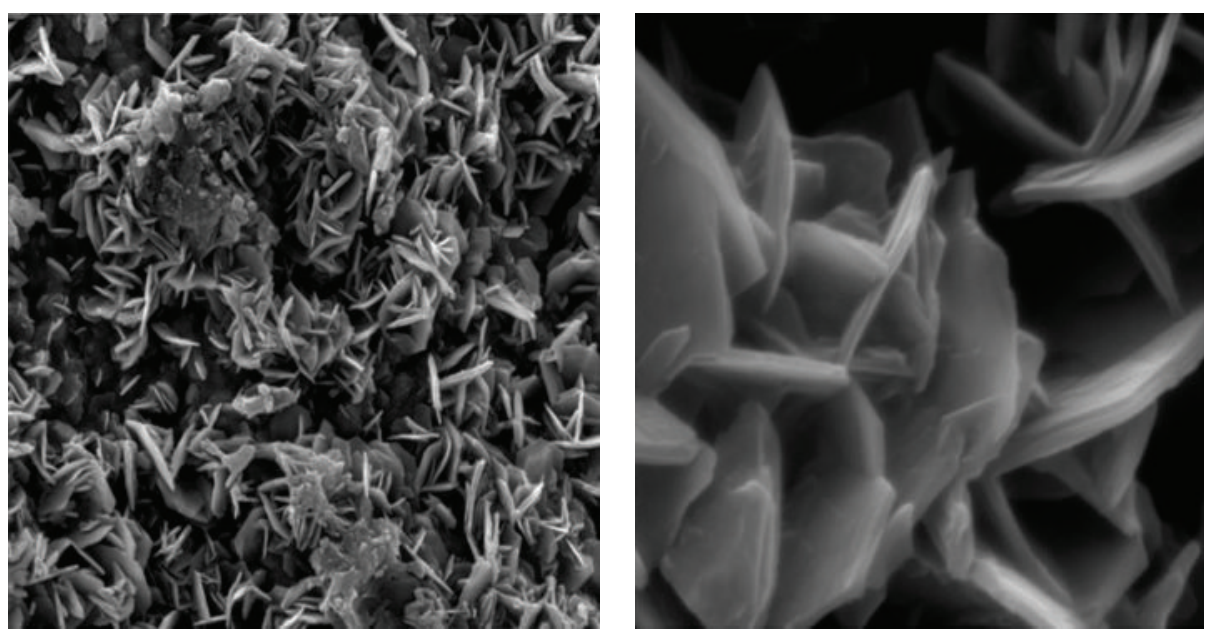

FIGURE 5: Whiskers growing on the surface when isothermally oxidised for $8 \mathrm{~h}$ at $1000^{\circ} \mathrm{C}$.

3.3. EDX Characterisation. X-ray analysis was carried out on the surface of the oxidised wires to obtain an elemental composition.

Table 2 shows data obtained from the EDX characterisation on the surface when isothermally oxidised for $16 \mathrm{~h}$ at $800^{\circ} \mathrm{C}-1200^{\circ} \mathrm{C}$ showing the increasing $\mathrm{Al}$ content with increase in temperature resulting in an increasing $\mathrm{Al} / \mathrm{Fe}$ ratio. The ratio of $\mathrm{Al} / \mathrm{Fe}$ increases by $40 \%( \pm 5 \%)$ with every temperature interval. However, the elemental concentration of Al does not increase rapidly particularly after $1000^{\circ} \mathrm{C}$.

Table 3 illustrates the varied elemental composition on the surface of the FeCrAl alloy wire when isothermally
TABLE 2: EDX data when wire is isothermally oxidised for $16 \mathrm{~h}$ at $800^{\circ} \mathrm{C}-1200^{\circ} \mathrm{C}$.

\begin{tabular}{lccccc}
\hline & $\mathrm{Al}$ & $\mathrm{Fe}$ & $\mathrm{Cr}$ & $\mathrm{O}$ & $\mathrm{Al} / \mathrm{Fe}$ \\
\hline $800^{\circ} \mathrm{C}$ & 25.7 & 40.1 & 14.4 & 18 & 0.7 \\
$900^{\circ} \mathrm{C}$ & 50.6 & 9.2 & 5.1 & 35.1 & 5.7 \\
$1000^{\circ} \mathrm{C}$ & 54.4 & 6.9 & 3.8 & 34.7 & 8.1 \\
$1200^{\circ} \mathrm{C}$ & 55.2 & 4.7 & 1.8 & 38.2 & 11.7 \\
\hline
\end{tabular}

oxidised at $1000^{\circ} \mathrm{C}$ for varying sampling times. With increasing time the concentration of Fe and $\mathrm{Cr}$ decreases. 
TABLE 3: EDX data when wire is isothermally oxidized for $0.5 \mathrm{~h}-16 \mathrm{~h}$.

\begin{tabular}{lccccc}
\hline & $\mathrm{Al}$ & $\mathrm{Fe}$ & $\mathrm{Cr}$ & $\mathrm{O}$ & $\mathrm{Al} / \mathrm{Fe}$ \\
\hline $0.5 \mathrm{~h}$ & 22.9 & 28.9 & 10.4 & 20.7 & 0.8 \\
$1 \mathrm{~h}$ & 37.1 & 25.9 & 11.8 & 21.1 & 1.4 \\
$2 \mathrm{~h}$ & 42.4 & 17.2 & 9.5 & 25.7 & 2.5 \\
$4 \mathrm{~h}$ & 44.8 & 17.7 & 9.2 & 29.3 & 2.5 \\
$8 \mathrm{~h}$ & 29.6 & 10.6 & 5.1 & 32.3 & 2.8 \\
$16 \mathrm{~h}$ & 54.5 & 6.9 & 3.8 & 34.8 & 8.1 \\
\hline
\end{tabular}

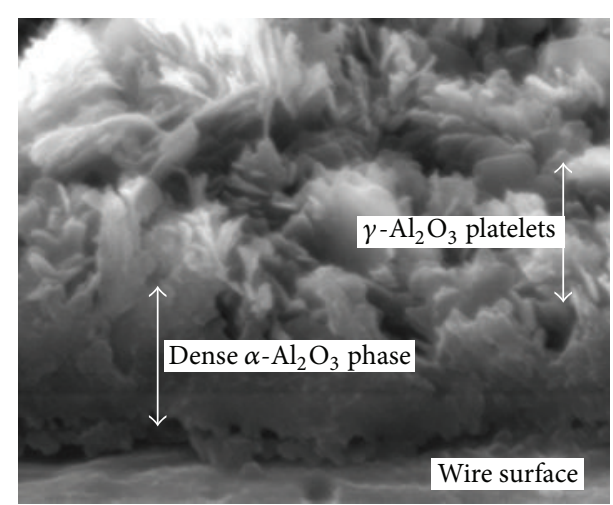

FIGURE 6: Dense oxide growth after $16 \mathrm{~h}$ of isothermal oxidation at $1000^{\circ} \mathrm{C}$.

The $\mathrm{Al} / \mathrm{Fe}$ ratio increases steadily with time. Initially there is a rapid increase in concentration of $\mathrm{Al}$ which stabilizes with time (see Figure 7).

3.4. XRD Characterization. Using the Philips X'Pert X-Ray Diffraction, experiments were performed on the samples in the $2 \theta$ range of $30^{\circ}$ and $50^{\circ}$ and a scanning speed of $0.0096^{\circ} /$ $\min$.

Figure 8 shows the varying intensity of peaks when samples are oxidised isothermally for $16 \mathrm{~h}$ between $800^{\circ} \mathrm{C}$ $1200^{\circ} \mathrm{C}$.

Figure 9 shows the varying intensity of peaks when samples are oxidised isothermally at $1000^{\circ} \mathrm{C}$ for $1 \mathrm{~h}-16 \mathrm{~h}$. With increasing time and temperature the peaks appear to be getting sharper indicating an increase in crystallite size and hence a decrease in surface area.

XRD data confirms the presence of transition aluminas on the surface of the wire. With increasing temperature and time periods the peaks obtained appeared to be getting sharper indicating a phase transformation to a more crystalline lower surface area $\alpha-\mathrm{Al}_{2} \mathrm{O}_{3}$.

\section{Discussion}

When FeCrAl alloy is exposed to high temperature in air, there is an inward diffusion of oxygen taking place on the surface. During the initial stages of oxidation due to the increased concentration of $\mathrm{Fe}$ and $\mathrm{Cr}$ ions and these ions tend to get preferentially oxidised. However, Al has a higher affinity for $\mathrm{O}$ when compared to $\mathrm{Fe}$ and $\mathrm{Cr}$ ions, thus gets preferentially oxidised with the passage of time resulting in an alumina oxide layer [12]. The $\mathrm{Cr}_{2} \mathrm{O}_{3}$ that is initially formed acts as nucleation centres for the $\mathrm{Al}_{2} \mathrm{O}_{3}$ [13]. Hence with increasing time, as the thickness of the alumina oxide layer increases, there appears to be a decreasing concentration of $\mathrm{Fe}$ and $\mathrm{Cr}$. The outward diffusion of $\mathrm{Al}$ and inward diffusion of $O$ result in an outward growth of an oxide layer on the surface of the wire. TGA data revealed a reduced weight change when oxidised at $800^{\circ} \mathrm{C}(0.037 \%)$. ESEM images (Figure 3(a)) also revealed a morphology which was very similar to the wire surface prior to any oxidation treatment. The growth of the alumina layer only initiates at temperatures greater than $800^{\circ} \mathrm{C}[14]$.

Isothermal oxidation at $1000^{\circ} \mathrm{C}$ for varied time periods resulted in a whisker-like morphology being formed across the surface of the wire. With increasing time the growth of the platelet-like structure was more uniform across the entire surface. EDX characterisation showed that with time the Al concentration increased on the surface.

Isothermal oxidation at $1000^{\circ} \mathrm{C}$ for shorter periods of time resulted in the growth of an oxide scale, but ESEM analysis revealed the morphology to be more flat which would not be suitable if a wash coat layer is to be applied. Increased time of exposure or very high temperature oxidation results in sintering of the oxide scale again rendering it unsuitable if the alloy is to be used for catalysis $[15,16]$. Work in the past suggests that the most suitable morphology on the alloy surface, when used as a catalytically support, is the growth of randomly oriented whiskers [15]. In this study (Figure 5), at a time period of $8 \mathrm{~h}$, there seems to be formed on the surface an even well-adhered layer of $\gamma-\mathrm{Al}_{2} \mathrm{O}_{3}$. This layer has a thickness of around 4-5 $\mu \mathrm{m}$ and a whisker-like morphology and appeared to have a high-surface area.

ESEM images also indicate a phase transformation taking place on the surface of the alloy wires. At $1100^{\circ} \mathrm{C}$ there appears to be a wrinkling effect taking place on the surface of the wire and the phase of alumina oxide present appears to be predominantly $\alpha-\mathrm{Al}_{2} \mathrm{O}_{3}$. Oxidation at $1200^{\circ} \mathrm{C}$ for $16 \mathrm{~h}$ resulted in thermal spallation. Exposure to high temperature oxidation for very long periods of time results in an increased consumption of $\mathrm{Al}$ ions resulting in critically low values of concentration of the ions present in the elemental state [17]. This causes an increased tensile stress in the oxide layer resulting in bits of the layer being ejected from the surface as can be seen from the ESEM image (Figure 3(d)).

The oxide morphology formed at different temperatures and time periods can be summarised in a graph (Figure 10). The graph is an indication of a suitable time period for different operating temperatures to obtain the required morphology. Solid line indicates where the morphology at the specific time and temperature is known, dotted lines are an extrapolation of available data sets, and experimental results are not available.

\section{Conclusion}

This work has shown the varied morphology of $\mathrm{Al}_{2} \mathrm{O}_{3}$ oxide layers grown on the surface of $\mathrm{FeCrAl}$ wire at temperatures between $800^{\circ} \mathrm{C}$ and $1200^{\circ} \mathrm{C}$. The growth of $\gamma-\mathrm{Al}_{2} \mathrm{O}_{3}$ after $8 \mathrm{~h}$ 


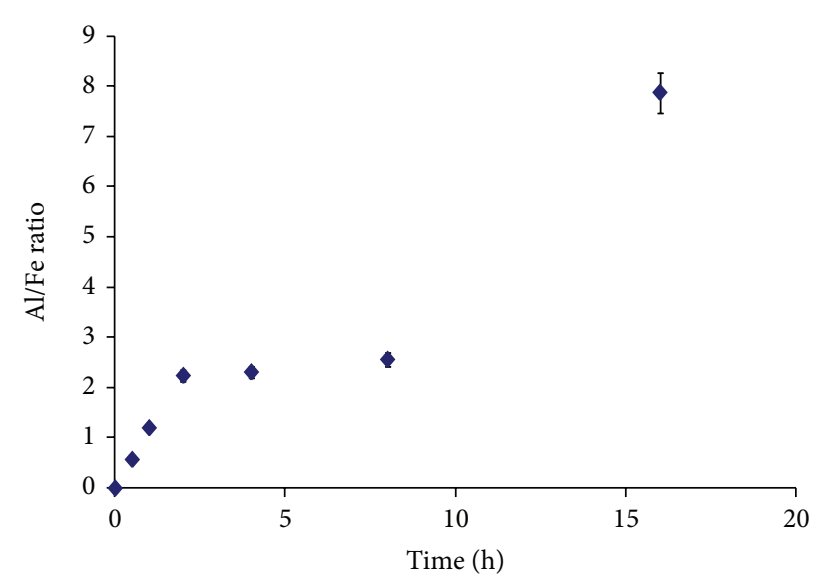

(a)

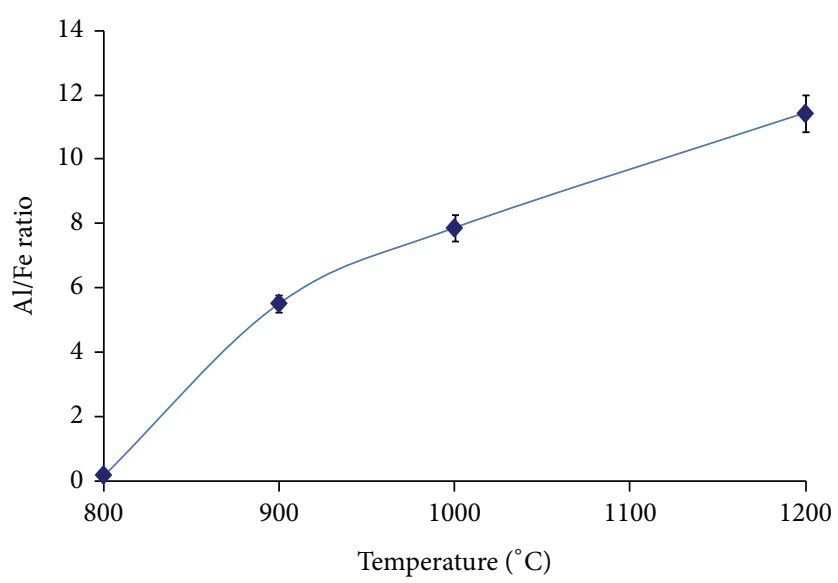

(b)

FIgURE 7: Varying $\mathrm{Al} / \mathrm{Fe}$ ratio with (a) time at $1000^{\circ} \mathrm{C}$ and (b) temperature at $800^{\circ} \mathrm{C}-1200^{\circ} \mathrm{C}$.

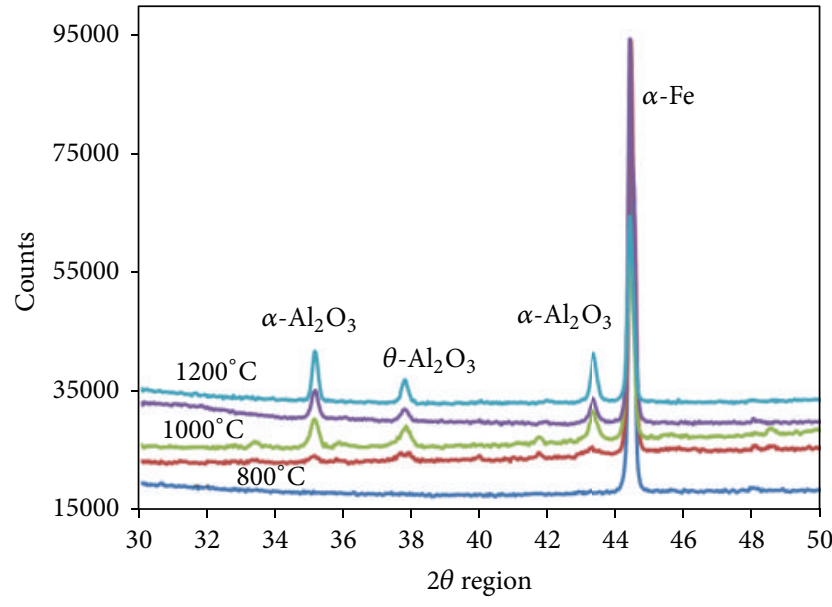

FIGURE 8: XRD peaks when wire is oxidised isothermally at $800^{\circ} \mathrm{C}-$ $1200^{\circ} \mathrm{C}$.

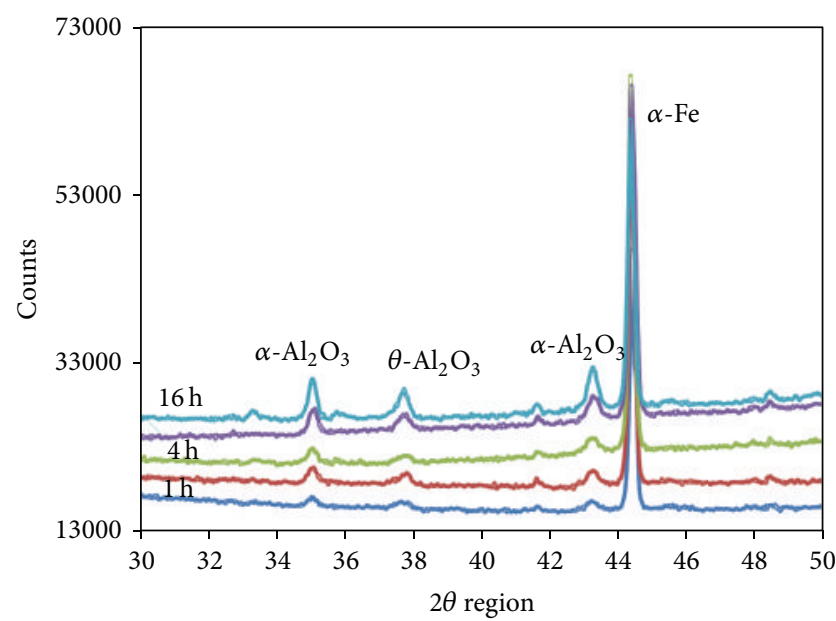

FIGURE 9: XRD peaks when wire is oxidized isothermally at $1000^{\circ} \mathrm{C}$ for $1 \mathrm{~h}-16 \mathrm{~h}$.

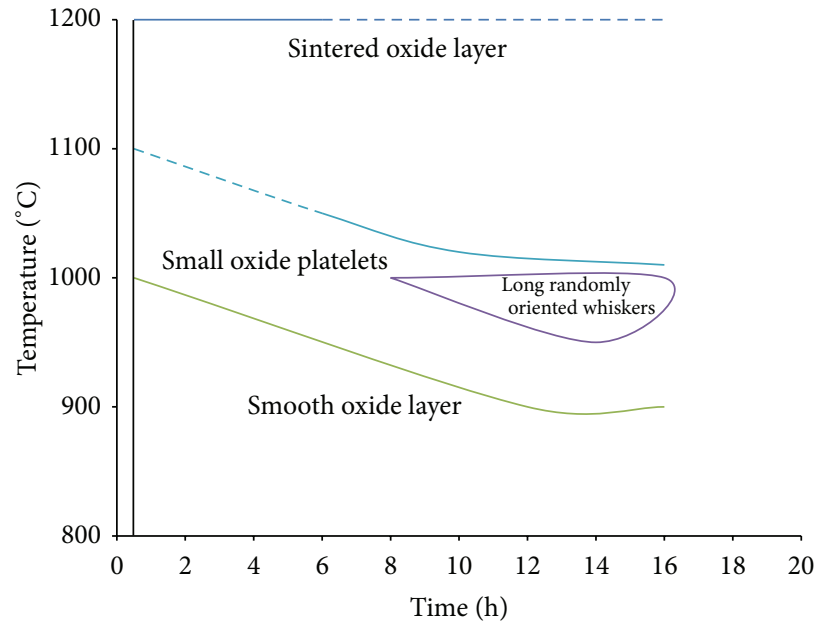

FIGURE 10: Change in oxide morphology at $800^{\circ} \mathrm{C}-1200^{\circ} \mathrm{C}$ for $0.5 \mathrm{~h}-$ $16 \mathrm{~h}$.

at $1000^{\circ} \mathrm{C}$ has been observed and the phase transformation from $\gamma-\mathrm{Al}_{2} \mathrm{O}_{3}$ to $\alpha-\mathrm{Al}_{2} \mathrm{O}_{3}$ also noted. This structured surface can be utilized as a catalytic support and a further wash coat layer can be applied if required. Further work is currently being carried out at the University of Manchester to test the structured support in endothermic catalytic cracking and dehydrogenation reactions.

\section{References}

[1] P. Avila, M. Montes, and E. E. Miró, "Monolithic reactors for environmental applications: a review on preparation technologies," Chemical Engineering Journal, vol. 109, no. 1-3, pp. 11-36, 2005.

[2] V. Meille, S. Pallier, G. V. S. C. Bustamante, M. Roumanie, and J. P. Reymon, "Deposition of $\gamma-\mathrm{Al}_{2} \mathrm{O}_{3}$ layers on structured supports for the design of new catalytic reactors," Applied Catalysis A, vol. 286, no. 2, pp. 232-238, 2005. 
[3] J. L. Williams, "Monolith structures, materials, properties and uses," Catalysis Today, vol. 69, no. 1-4, pp. 3-9, 2001.

[4] R. M. Heck, S. Gulati, and R. J. Farrauto, "The application of monoliths for gas phase catalytic reactions," Chemical Engineering Journal, vol. 82, no. 1-3, pp. 149-156, 2001.

[5] A. Białas, W. Osuch, W. Łasocha, and M. Najbar, "The influence of the $\mathrm{Cr}-\mathrm{Al}$ foil texture on morphology of adhesive $\mathrm{Al}_{2} \mathrm{O}_{3}$ layers in monolithic environmental catalysts," Catalysis Today, vol. 137, no. 2-4, pp. 489-492, 2008.

[6] F. Liu, H. Götlind, J. E. Svensson, L. G. Johansson, and M. Halvarsson, "Early stages of the oxidation of a FeCrAlRE alloy (Kanthal AF) at $900^{\circ} \mathrm{C}$ : a detailed microstructural investigation," Corrosion Science, vol. 50, no. 8, pp. 2272-2281, 2008.

[7] H. El Kadiri, R. Molins, Y. Bienvenu, and M. F. Horstemeyer, "Abnormal high growth rates of metastable aluminas on FeCrAl alloys," Oxidation of Metals, vol. 64, no. 1-2, pp. 63-97, 2005.

[8] J. Jedlinski, "The oxidation behaviour of FeCrAl "alumina forming” alloys at high temperatures," Solid State Ionics, vol. 101103, part 2, pp. 1033-1040, 1997.

[9] V. Meille, "Review on methods to deposit catalysts on structured surfaces," Applied Catalysis A, vol. 315, pp. 1-17, 2006.

[10] D. Zhang, L. Zhang, B. Liang, and Y. Li, "Effect of acid treatment on the high-temperature surface oxidation behavior of FeCrAlloy foil used for methane combustion catalyst support," Industrial and Engineering Chemistry Research, vol. 48, no. 10, pp. 5117-5122, 2009.

[11] X. Wu, D. Weng, L. Xu, and H. Li, "Structure and performance of $\gamma$-alumina washcoat deposited by plasma spraying," Surface and Coatings Technology, vol. 145, no. 1-3, pp. 226-232, 2001.

[12] E. Airiskallio, E. Nurmi, M. H. Heinonen et al., "Third element effect in the surface zone of Fe-Cr-Al alloys," Physical Review B, vol. 81, no. 3, Article ID 033105, 4 pages, 2010.

[13] H. Asteman and M. Spiegel, "A comparison of the oxidation behaviours of $\mathrm{Al}_{2} \mathrm{O}_{3}$ formers and $\mathrm{Cr}_{2} \mathrm{O}_{3}$ formers at $700^{\circ} \mathrm{C}-$ oxide solid solutions acting as a template for nucleation," Corrosion Science, vol. 50, no. 6, pp. 1734-1743, 2008.

[14] G. Berthomé, E. N'Dah, Y. Wouters, and A. Galerie, “Temperature dependence of metastable alumina formation during thermal oxidation of FeCrAl foils," Materials and Corrosion, vol. 56, no. 6, pp. 389-392, 2005.

[15] L. R. Chapman, C. W. Vigor, and J. F. Watton, "Enhanced oxide whisker growth on peeled Al-containing stainless steel foil," US Patent 4331631, 1982.

[16] G. L. Vaneman and D. R. Sigler, "Accelerated whisker growth on iron-chromium-aluminum alloy foil,” US Patent 4915751, 1990.

[17] C. Mennicke, D. R. Clarke, and M. Rühle, "Stress relaxation in thermally grown alumina scales on heating and cooling $\mathrm{FeCrAl}$ and FeCrAlY alloys," Oxidation of Metals, vol. 55, no. 5-6, pp. 551-569, 2001. 

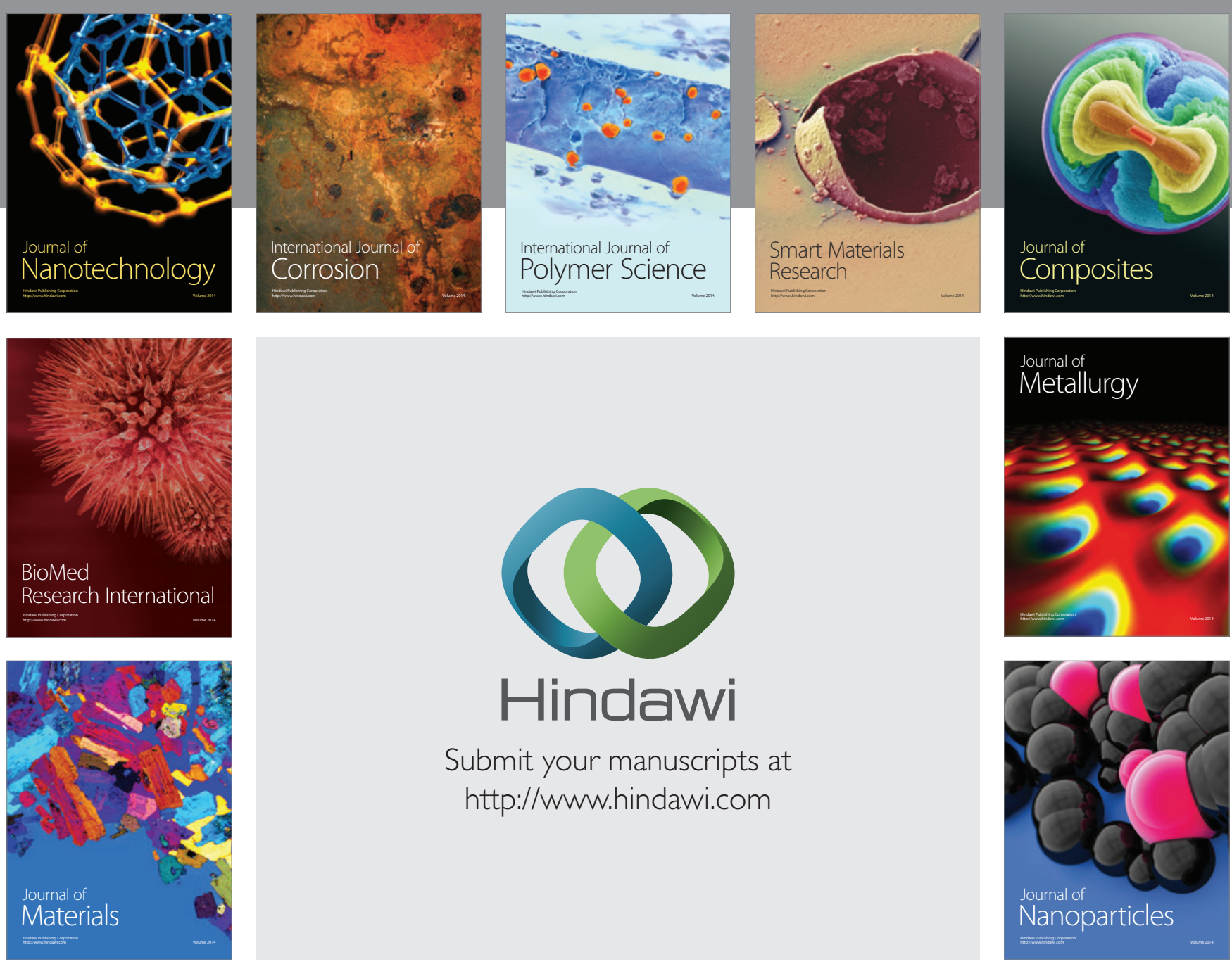

Submit your manuscripts at http://www.hindawi.com
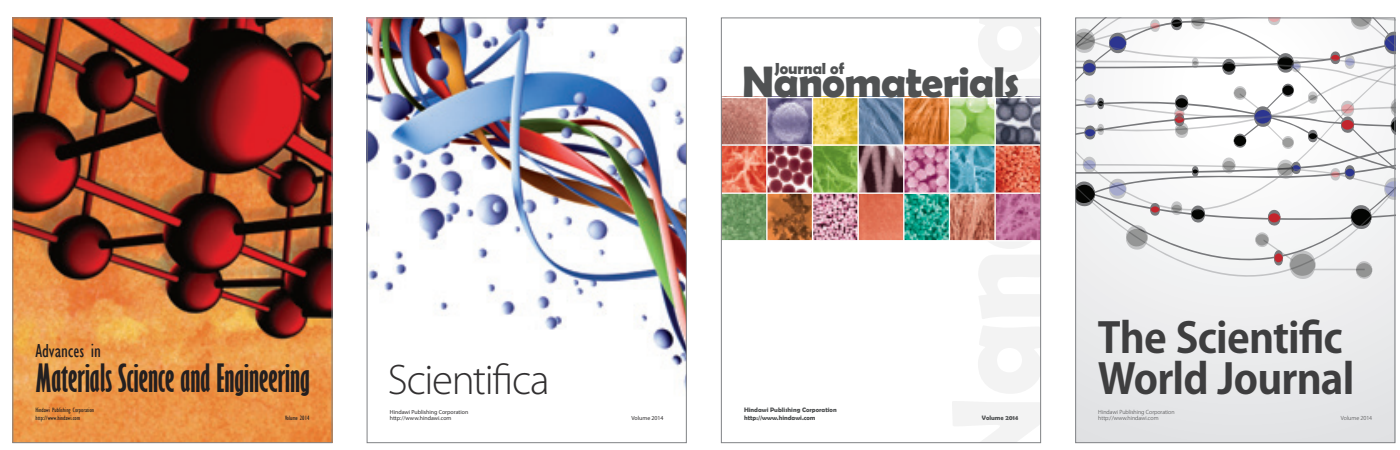

\section{The Scientific World Journal}
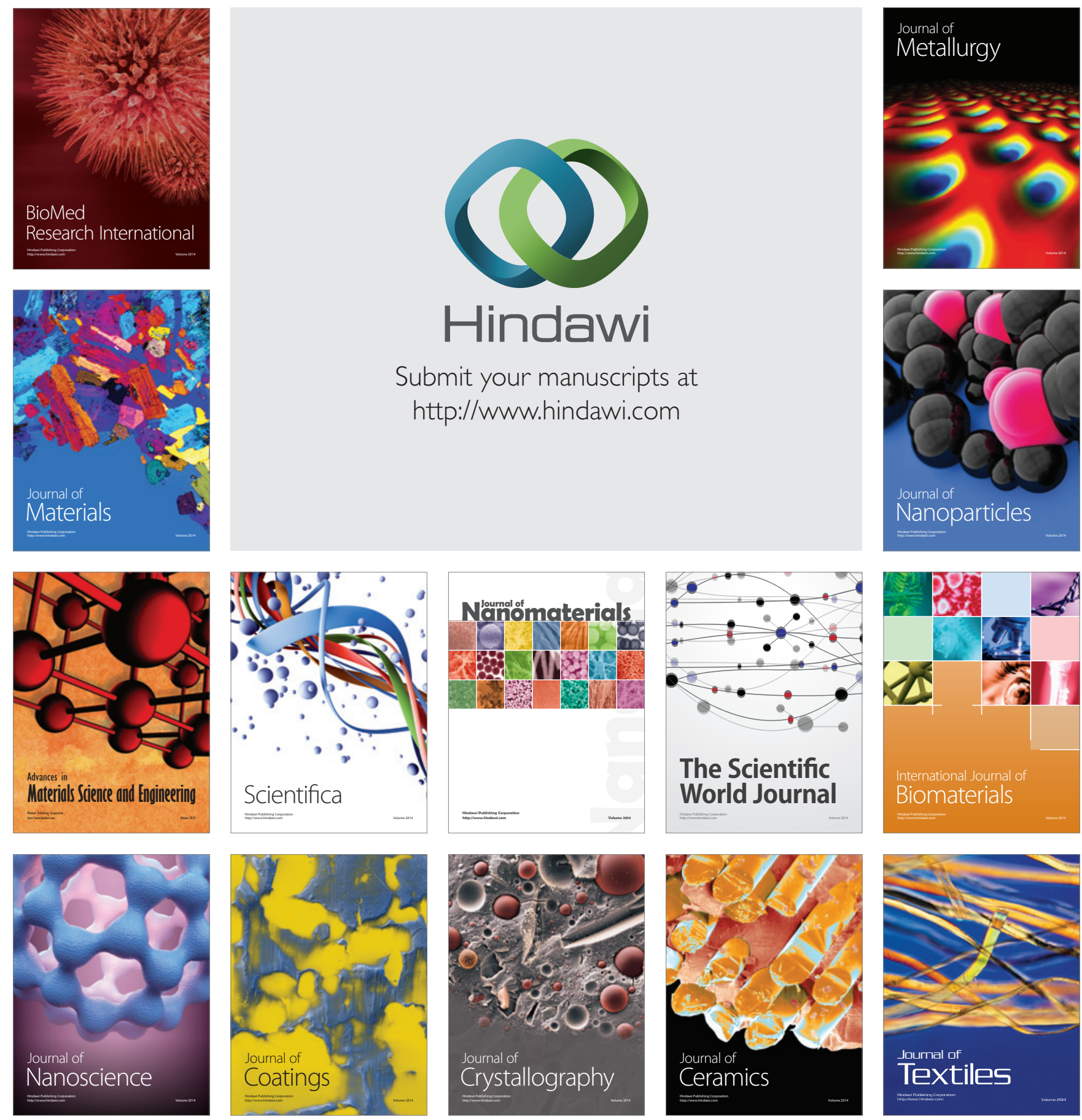